\title{
Comparative Analysis of Various Evolutionary Techniques of Load Balancing: A Review
}

\author{
Manvi Mishra \\ HOD CS/IT Deptt \\ SRMSWCET Bareilly \\ INDIA
}

\author{
Shivali \\ Agarwal \\ Research Scholar \\ SRMSWCET \\ Bareilly INDIA
}

\author{
Payal Mishra \\ Research Scholar \\ SRMSWCET \\ Bareilly INDIA
}

\author{
Shalini Singh \\ Research Scholar \\ SRMSWCET \\ Bareilly INDIA
}

\begin{abstract}
For a decade swarm Intelligence deals with the design of intelligent multi-agent systems by taking inspiration from the collective behaviors of social insects and other animal societies. They are characterized by a decentralized way of working that mimics the behavior of the swarm. Swarm Intelligence is a successful paradigm for the algorithm with complex problems. The aim of this review paper is to analyze and compare various swarm intelligence evolutionary techniques of load balancing and conclude the best optimum technique among them. A brief introduction of load balancing and its various evolutionary techniques are presented and summarized.
\end{abstract}

\section{Keywords}

Load Balancing; Evolutionary Techniques; Swarm Intelligence.

\section{INTRODUCTION}

Load balancing is a technique to distribute workload evenly across two or more computers, network links, CPU's or other resources in order to get optimal resource utilization, maximum throughput, minimum response time, minimum communication delays, minimum execution time and avoiding overload[1][2]. Load balancing is useful when dealing with redundant communications links. For example, a bank may have multiple Internet connections ensuring network access even if one of the connections fails, a failover arrangement means that one link is designated for normal use, while the second link is used only if the first one fails. With load balancing, both links can be in use all the time. Load balancing attempts to improve the performance of a distributed heterogeneous system by using the processing power of the entire system to smooth out the periods of high congestion at individual nodes [3][4].This is achieved by transferring some of the workload of heavily loaded nodes to other nodes for processing. The decisions to balance loads among the nodes are either static or dynamic [5][6]. A static decision is independent of the current system state. The static load balancing is simple and easy to analyze with queuing models, but its potential benefit is limited [7][8]. On the other hand, a dynamic decision is dependent on the system state. When a dynamic load balancing is used, an over loaded node may transfer its jobs to other nodes using the information on the current system state[9][10].Static methods are like putting a round robin DNS, using virtual servers and also using evolutionary techniques of optimization. Traditional methods used in optimization are deterministic, fast and give exact answers but often tends to get stuck on local optima. The evolutionary techniques gives a dynamic view of Load Balancing. The evolutionary techniques are Ant Colony Optimization technique, Genetic algorithm technique, Particle Swarm Optimization technique ,diffusion algorithm technique, tabu search technique, Hybrid Particle Swarm Optimization technique etc[11].The rest of the paper is organized as follows: Section 2 presents the review of literature, Section 3 comprises of comparative analysis of various evolutionary techniques, conclusion and future work are given in section 4 .

\section{REVIEW OF LITERATURE}

Substantial work has been done on load balancing in the past years. Various researchers and scientists all over the world has been presented their articles and papers on load balancing techniques which are described below:

\subsection{Genetic Algorithm}

A Genetic Algorithm (GA) is a search algorithm technique based on the principles of evolution and natural genetics. It was initially proposed by John Holland in 1970's [12]. GA reflects some of the innovative flair of a human search by using the survival of fittest techniques combined with a structured yet randomized information exchange [13]. GA technique is randomized and efficiently exploit historical information to speculate on new search points with expected improvement [14][15]. GA techniquework from a database of points simultaneously, climbing many peaks in parallel. The probability of finding a false peak is reduced involving nothing more complex than copying strings and swapping partial strings. The two main attraction of GA technique that are point to point are simplicity of operation and power of effect [16].

\subsection{Ant Colony Optimization}

Ant colony optimization (ACO) is a Swarm Intelligence technique which is inspired from the foraging behaviour of real ant colonies [17]. The ants deposit pheromone on the ground in order to mark the route from the nest to food that is followed by 
other members of the colony. ACO exploits an optimization mechanism for solving discrete optimization problems in various engineering domain[18].The ACO differs from the classical ant system in the sense that here the pheromone trails are updated in two ways. Firstly, when ants construct a tour they locally change the amount of pheromone on the visited edges by a local updating role. Secondly, after all the ants have built their individual tours, a global updating rule is applied to modify the pheromone level on the edges that belong to the best ant tour found so far. An artificial Ant Colony System (ACS) is an agent-based system, which simulates the natural behavior of ants and develops mechanisms of cooperation and learning. ACS was proposed by Dorigo et al. in 1997 as a new heuristic technique to solve combinatorial optimization problems. It is found to be both robust and versatile in handling a wide range of combinatorial optimization problems [19][20].

\subsection{Diffusion Algorithm}

This load balancing technique was introduced by Cybenko and Boillat [21].It also balance the load among the nodes in a system. The idea behind this technique is that in each round, the overloaded node exchanges its excess load with their neighbors individually. The advantage of DA technique lies in the collection of information from the nodes in a system. The information policies will have higher impact on earlier completion of load balancing algorithm. The objective of the diffusion load balancing technique in both static load situations and in dynamic load situations is to keep the nodes to contain an equal number of loads as quickly as possible. Lots of work has been already done under the assumption that every edge is allowed only to forward one load unit per round or a constant number of loads can be passed by each node [22][23].

\subsection{Tabu Search}

Tabu search (TS) technique was introduced by Glover in 1986 [24]. It is based on the premise that problem solving must incorporate adaptive memory and responsive exploration. The adaptive memory feature of TS allows the implementation of procedures that are capable of searching the solution space economically and effectively. TS contrasts with memory less designs that heavily rely on semirandom processes that implement a form of sampling [25]. The emphasis on responsive exploration in TS technique in a deterministic or probabilistic implementation, derives from the supposition that a bad strategic choice can often yield more information than a good random choice. It may be directly applied to virtually any kind of optimization problem. It is a meta-heuristic that guides a local heuristic search procedure to explore the solution space beyond local optimality [26].

\subsection{Artificial Bee Colony}

Artificial Bee Colony (ABC) technique is a swarm based metaheuristic technique. It was introduced by Karaboga in 2005 [27]. It simulates the foraging behaviour of honey bees. The technique has three phases namely employee bee, onlooker bee and scout bee. In the employed bee and the onlooker bee phases, bees exploit the sources by local searchers in the neighbourhood of the solutions selected based on deterministic selection. Scout bee phase is an analogy of abandoning exhausted food sources in the foraging process, solutions that are not beneficial anymore for search progress are abandoned and new solutions are inserted instead of them to explore new regions in the search space. The technique has a wellbalanced exploration and exploitation ability [28].

\subsection{Intelligent Water Drop}

Intelligent Water drop (IWD) technique for load balancing is swarm based optimization technique. It is inspired by natural rivers and how they find almost optimal paths to their destination. These near optimal or optimal paths follow from actions and reactions occuring among the water drops and the water drops with their riverbed [29]. In the IWD technique, several artificial water drops cooperate to change their environment in such a way that the optimal path is revealed as the one with the lowest soil on its links.IWD has two important properties. Firstly, soil i.e the amount of soil it carries. Secondly, velocity i.e the velocity with which it is moving [30]. The IWD soil is increased by removing some soil of the path joining the two locations. The amount of soil added to the IWD is inversely proportional to the time needed for the IWD to pass from its current location to the next location. This duration of time is calculated by the simple laws of physics for linear motion. Thus, the time taken is proportional to the velocity of the IWD and inversely proportional to the distance between the two locations. Another mechanism that exists in the behavior of an IWD is that it prefers the paths with low soils on its beds to the paths with higher soils on its beds. Uniform random distribution is used to implement the behavior of path choosing among the available paths of soil. The lower the soil of the path, the more chance it has for being selected by the IWD [31].

\subsection{Particle Swarm Optimization}

The Particle swarm optimization(PSO) is a stochastic, population-based computer algorithm modelled on swarm intelligence that finds a solution of optimization problem in a search space or model. It is based on socialpsychological principles and provides insights into social behavior, as well as contributing to engineering applications [20]. The particle swarm optimization technique is described in 1995 by James Kennedy and Russell C. Eberhart [32]. A communication structure or social network is defined for each individual to interact. These individuals are also known as the particle. An iterative process to improve these candidate solutions is set in motion. The particles iteratively evaluate the fitness of the candidate solutions and remember the location where they had their best success. The individual's best solution is called the particle best or the local best. Each particle makes this information available to their neighbors according to the local best solution [33].

2.8 Hybrid Particle Swarm Optimization Hybrid particle swarm optimization (HPSO) is proposed by making use of PSO and some other techniques such as simulated annealing technique, Hill Climbing technique etc and it has been claimed that the hybridization yields a better result than normal PSO [34]. This paper uses the hybridization of PSO and the Simulated Annealing Algorithm. PSO has a strong ability to find the most optimistic result. The PSO technique may be combined with some other evolutionary optimization technique to yield an even better performance. Simulated Annealing (SA) may find the global optimum using stochastic search technology from the means of probability.SA technique has a strong ability to find the local optimistic result. Combining PSO and SA leads to the combined effect of the good global search algorithm and the good local search algorithm, which yields a promising result [35]. 


\subsection{Max-Min Particle Swarm Optimization}

Max-Min particle swarm optimization (Max-Min PSO) is based on the task scheduling in grid environment. Grid Scheduling is a critical design issue of grid computing[36]. The major objective of grid scheduling is to reduce the makespan, cost and increase the number of tasks completed within deadline. The algorithm is developed based on PSO to find a proper resource allocation to jobs in Grid Environment. When the load on the resources are balanced with Max-Min PSO better makespan is achieved[37].

\section{COMPARATIVE ANALYSIS OF VARIOUS EVOLUTIONARY TECHNIQUES}

Comparative analysis of evolutionary techniques of load balancing is summarized in Table 1. In particular, advantages, limitations, issues etc are analyzed and compared to the other techniques.

Table 1: Comparative analysis of evolutionary technique

\begin{tabular}{|c|c|c|c|c|c|}
\hline S.No & Technique & Author & Issues & Advantage & Limitation \\
\hline 1. & $\begin{array}{l}\text { GENETIC } \\
\text { ALGORIHM } \\
\text { (GA) }\end{array}$ & $\begin{array}{l}\text { Andrew J. Page , } \\
\text { Thomas M. Keane } \\
\text { et al. }\end{array}$ & $\begin{array}{l}\text { Window size, Two } \\
\text { point cross over, } \\
\text { Evolution Period, } \\
\text { Max stale period. }\end{array}$ & $\begin{array}{l}\text { Minimizes execution time } \\
\text { \&communication cost } \\
\text { \&maximizes average } \\
\text { processor utilisation \& } \\
\text { system throughput[38]. }\end{array}$ & $\begin{array}{l}\text { Incur extra storage and } \\
\text { processing requirement at } \\
\text { the scheduling node; } \\
\text { The saving may outweight } \\
\text { the extra overhead } \\
\text { considering the ever } \\
\text { decreasing cost of storage } \\
\text { and processing } \\
\text { power[16][38]. }\end{array}$ \\
\hline 2. & $\begin{array}{l}\text { ANT COLONY } \\
\text { OPTIMIZATION } \\
(\mathrm{ACO})\end{array}$ & $\begin{array}{l}\text { V.Selvi } \\
\text { Dr.R.Umarani }\end{array}$ & $\begin{array}{l}\text { Execution time, } \\
\text { Maximum execution } \\
\text { time, idle time. }\end{array}$ & $\begin{array}{l}\text { Inherent parallelism; } \\
\text { Positive feedback accounts } \\
\text { for rapid discovery of good } \\
\text { solution; Efficient for TSP } \\
\text { and similar problems; } \\
\text { Can be used in dynamic } \\
\text { application[20]. }\end{array}$ & $\begin{array}{l}\text { Theoretical analysis is } \\
\text { difficult; Sequences of } \\
\text { random decision decisions; } \\
\text { Probability on distribution } \\
\text { changes by iteration; } \\
\text { Time to convergence } \\
\text { uncertain[20]. }\end{array}$ \\
\hline 3. & $\begin{array}{l}\text { DIFFUSION } \\
\text { ALGORITHM } \\
\text { (DA) }\end{array}$ & $\begin{array}{l}\text { P.Neelakantan, } \\
\text { Martin et al. }\end{array}$ & $\begin{array}{l}\text { It performs better in } \\
\text { terms of time taken to } \\
\text { balance the load, } \\
\text { Minimizing the load } \\
\text { variance among the } \\
\text { nodes and } \\
\text { maximizing the } \\
\text { throughput and } \\
\text { execution time[23]. }\end{array}$ & $\begin{array}{l}\text { Reducing communication } \\
\text { overhead[23]. }\end{array}$ & $\begin{array}{l}\text { It is difficult to provide } \\
\text { clean general solution to } \\
\text { this problem[22]. }\end{array}$ \\
\hline 4. & $\begin{array}{l}\text { TABU SEARCH } \\
\text { (TS) }\end{array}$ & $\begin{array}{l}\text { Fred W Glover, } \\
\text { Hong Rui Liu et al. }\end{array}$ & $\begin{array}{l}\text { Local } \quad \text { search } \\
\text { procedure, aspiration } \\
\text { conditions, maximum } \\
\text { size of tabulist, } \\
\text { stopping rule. }\end{array}$ & $\begin{array}{l}\text { For large and more difficult } \\
\text { problems;Can be applied to } \\
\text { both discrete and } \\
\text { continuous solution spaces; } \\
\text { Allow non improving } \\
\text { solution to be accepted in } \\
\text { order to escape from a local } \\
\text { optimum[24][25]. }\end{array}$ & $\begin{array}{l}\text { No. Of iteration could be } \\
\text { very large,Global optimum } \\
\text { may not be found, depends } \\
\text { on the parameter settings, } \\
\text { Incur extra storage } \\
\text { \&processing } \\
\text { power[24][25]. }\end{array}$ \\
\hline
\end{tabular}




\begin{tabular}{|c|c|c|c|c|c|}
\hline 5. & $\begin{array}{l}\text { ARTIFICIAL BEE } \\
\text { COLONY } \\
(\mathrm{ABC})\end{array}$ & $\begin{array}{l}\text { Dervis Karaboga, } \\
\text { Bahriye Akay }\end{array}$ & $\begin{array}{l}\text { Colony } \\
\text { size, maximum cycle } \\
\text { number and limit. }\end{array}$ & $\begin{array}{l}\text { It produces better results on } \\
\text { multimodal and } \\
\text { Multidimensional } \\
\text { optimisation problems. } \\
\text { It is as simple and flexible } \\
\text { as PSO and also employs } \\
\text { less control parameters[28]. }\end{array}$ & $\begin{array}{l}\text { It is found effective only in } \\
\text { solving small to medium } \\
\text { sized generalisation } \\
\text { assignment problems not } \\
\text { for large and complex } \\
\text { problem[39]. }\end{array}$ \\
\hline 6. & $\begin{array}{l}\text { INTELLIGENT } \\
\text { WATER DROP } \\
\text { (IWD) }\end{array}$ & $\begin{array}{l}\text { S. Rao Rayapudi, } \\
\text { Shah Hosseini }\end{array}$ & Soil, velocity. & $\begin{array}{l}\text { Best choice for finding } \\
\text { optimial solution; } \\
\text { In order to solve services } \\
\text { composition IWD algo are } \\
\text { used; Higher coorectness } \\
\text { value ,feasibility and } \\
\text { effectiveness than PSO[29]. }\end{array}$ & $\begin{array}{l}\text { Only for web service } \\
\text { composition[31]. }\end{array}$ \\
\hline 7. & $\begin{array}{l}\text { PARTICLE } \\
\text { SWARM } \\
\text { OPTIMIZATION } \\
\text { (PSO) }\end{array}$ & $\begin{array}{l}\text { Millie Pant, } \\
\text { Dr.R.Umarani et al. }\end{array}$ & $\begin{array}{l}\text { Makespan,cost, } \\
\text { Deadline. }\end{array}$ & $\begin{array}{l}\text { It is very simple, have no } \\
\text { overlapping and mutation } \\
\text { calculation, it adopts the } \\
\text { real no. code and it is } \\
\text { decided directly by the } \\
\text { solution[20]. }\end{array}$ & $\begin{array}{l}\text { It suffers from the } \\
\text { problem of premature } \\
\text { convergence, } \\
\text { particularly in case of } \\
\text { multimodal } \\
\text { optimization } \\
\text { problems[33][30]. }\end{array}$ \\
\hline 8. & $\begin{array}{l}\text { HYBRID PSO } \\
\text { (HPSO) }\end{array}$ & $\begin{array}{l}\text { P.Visalakshi, } \\
\text { S.N.Sivanandan }\end{array}$ & Cost & $\begin{array}{l}\text { It is a global and local } \\
\text { search algo which provides } \\
\text { most optimistic result, } \\
\text { cost effective[34]. }\end{array}$ & $\begin{array}{l}\text { Success rates are less, more } \\
\text { running time[34][35]. }\end{array}$ \\
\hline 9. & MAX- MIN PSO & $\begin{array}{l}\text { C.Kalpana, } \\
\text { U.Karthick Kumar } \\
\text { et al. }\end{array}$ & $\begin{array}{l}\text { Makespan, Cost, } \\
\text { Time Scheduling and } \\
\text { other Qos parameters. }\end{array}$ & $\begin{array}{l}\text { Better makespan } \\
\text { Cost and Time } \\
\text { Reduction[36][37]. }\end{array}$ & - \\
\hline
\end{tabular}




\section{CONCLUSIONS AND FUTURE WORK}

In this review paper nine evolutionary techniques of load balancing are analyzed and compared. The work deduce Max-Min PSO to be the recent and optimum load balancing technique. Better makespan is achieved when the load on the resources are balanced. It provides the best result in terms of cost and time reduction. Future work may also focus on reliability, optimum cost, throughput, quality of services constraints and different job error ratio.

\section{REFERENCES}

[1] Songnian Zhou, Domenico Ferrari, “ An Empirical investigation of Load Indices for Load Balancing Applications", Performance '87, Proc. Of the 12th IFIP WG7.3, International Symposium on Computer Performance Modeling Measurement and Evaluation, Brussels, Belgium,pp. 515-528, 1987.

[2] Songnian Zhou, Domenico Ferrari, “ An Experimental Study of Load Balancing Performance", Tech.Rept, No. UCB/CSD 87/336, January 1987.

[3] Gururaj S. Rao, Harold S. Stone And T.C.Hu", Assignment of Tasks in A Distributed Processor System With Limited Memory", IEEE Trans. On Computers, Vol. C28, No. 4, April 1979.

[4] Lionel M. Ni, Chong-Wei, Xu And Thomas B.Gendreau " A Distributed Drafting Algorithm for Load Balancing", IEEE Trans. on Software Engineering, Vol. SE -11, No. 10, October 1985.

[5] Asser N. Tantawi And Don Towsley, " Optimal Static Load Balancing in Distributed Computer Systems",Journal of the Association for Computing Machinery, Vol.32, No. 2 , April 1985.

[6] Kang G. Shin And Yi-Chien Chang, "Load Sharing in Distributed Real - Time Systems with State-Change Broadcasts", IEEE Trans. on Computers, Vol.38 , No. 8, August 1989.

[7] Shlomit S Pinter And Yaron Woltstahl, "On Mapping Processes to Processor in Distributed Systems", International Journal of Parallel Programming, Vol. 16, No.1, 1987.

[8] Ming-Syan Chen And Kand G. Shin," Subcube Allocation and Task Migration in Hypercube Multiprocessor", IEEE Trans. on Computers, Vol. 39, No. 9,September 1990.

[9] Derek L. Eager And Edward D. Lazowska And John Zahorjan, " Adaptive Load Sharing in Homogeneous Distributed Systems", IEEE Trans. On Software Engineering, Vol. SE- 12, No. 5, May 1986.

[10] Jian Xu And Kai Hwang," Heuristic Methods for Dynamic Load Balancing in A Message Passing Multicomputer", Journal of Parallel and Distributed Computing 18, 1-13(1993).

[11] Mourad Kara, "Using Dynamic Load Balancing in Distributed Information systems",
University of Leeds School of Computer Studies Research Report Series, Report 94.18, May 1994.

[12] J.H. Holland, Adaptation in Natural and Artificial Systems. Univ. of Michigan Press, 1975.

[13] M.D. Kidwell And D.J. Cook, ${ }^{\text {a} G e n e t i c ~ A l g o r i t h m ~}$ for Dynamic Task Scheduling, ${ }^{\circ}$ Proc. IEEE 13th Ann. Int'l Phoenix Conf. Computers and Comm., pp. 61-67, 1994.

[14] D.E. Goldberg, Genetic Algorithms in Search, Optimization, and Machine Learning. Reading, Mass.: Addison-Wesley, 1989.

[15] Z. Michalewicz, Genetic Algorithms + Data Structures $=$ Evolution Programs, second ed. Berlin: Springer-Verlag, 1994.

[16] Albert Y. Zomaya, Senior Member, IEEE, and Yee- Hwei, The Observations on Using Genetic Algorithms for Dynamic

Load-Balancing,IEEE

TRANSACTIONS ON PARALLEL AND DISTRIBUTED SYSTEMS VOL. 12, NO. 9, SEPTEMBER 2001.

[17] M.Dorigo,V.Maniezzo,Et i,Ant system:optimization by a colony of
cooperating agents,IEEE systems,Mna and Cybernetics-Part B,volume 26,numero 1,pages 29-41,1996.

[18] D. Ramesh, A. Krishnan, Optimal Parameter Identification in Ant Colony Optimization for Load Balancing in Grid Computing. European Journal of Scientific Research ISSN 1450-216X Vol.75 No.3 (2012), pp. 370-376@ EuroJournals Publishing, Inc. 2012.

[19] Al-Dahoud Ali And Mohamed A. Belal, Multiple Ant Colonies Optimization for Load Balancing in Distributed Systems". ICTA'07, April 12-14, Hammamet, Tunisia.

[20] V.Selvi Dr.R.Umarani, Comparative Analysis of Ant Colony and Particle Swarm Optimization Techniques. International Journal of Computer Applications (0975-8887) Volume 5- No.4, August 2010.

[21] G.Cybenko, Load balancing for distributed memory multiprocessors. Journal of Parallel and Distributed Computing, 7:279-301, 1989.

[22] Berenbrink, P. and Friedetzky, T. and Martin, R. (2005) ,Dynamic diffusion load balancing.', in Automata, languages and programming : $32^{\text {nd }}$ International Colloquium, ICALP 2005, 11-15 July 2005, Lisbon, Portugal ; proceedings. Berlin: Springer, pp. 1386-1398.

[23] P. Neelakantan Department of CSE, SVUCE, Tirupati, India Load Balancing in Distributed Systems using Diffusion Technique International Journal of Computer Applications (0975 - 8887) Volume 39- No.4, February 2012.

[24] Glover F.1986.Future Paths for Integer Programming and Links to Artificial Intelligence.Computers and Operations 
Research.Vol.13,pp.533-549.

[25] Hansen,P.1986.The Steepest Ascent Mildest Descent Heuristic for Combinatorial Programming.Congress on Numerial Methods in Combinatorial Optimization,Capri,Italy.

[26] Fred Glover, Manuel Laguna, Principles of Tabu Search. Dpto. de Estadística e Investigación Operativa, Facultad de Matemáticas, Universidad de Valencia, Dr. Moliner 50, 46100 Burjassot (Valencia) Spain.

[27] Karaboga, Dervis (2010)Artificial bee colony algorithmScholarpedia, 5(3): 6915.

[28] Artificial Bee Colony Dervis Karaboga*, Bahriye Akay A comparative study of Artificial Bee Colony algorithm,0096-3003/\$-see front matter_Elsevier inc. Doi:10.1016/j.amc.2009.03.090

[29] Shah-Hosseini, Hames (2009). "The intelligent water drops algorithm: a nature-inspired swarm-

based optimization algorithm". International Journal of Bio- Inspired Computation 1 (1/2) : 71 79.

[30] Liu, H., Abraham, A., Zhang, W.: A Fuzzy Adaptive Turbulent Particle Swarm Optimization. International Journal of Innovative Computing and Applications 1(1),39-47 (2007).

[31] S. Rao Rayapudi, An Intelligent Water Drop Algorithm for Solving Economic Load Dispatch Problem. International Journal of Electrical and Electronics Engineering 5:1 2011.

[32] Kennedy, J., Eberhart, R.C.: Particle Swarm Optimization. In: IEEE International Conference on Neural Networks (Perth, Australia), IEEE Service Center, Piscataway,NJ, pg. IV, pp. 1942-1948 (1995).

[33] Millie Pant, Radha Thangaraj, and Ajith Abraham, Particle Swarm Optimization: Performance Tuning and Empirical Analysis. A. Abraham et al. (Eds.): Foundations of
Comput. Intel. Vol. 3, SCI 203, pp. 101-128( Springer-Verlag Berlin Heidelberg 2009.

[34] P.Visalakshi,S.N.Sivanandan,Dynamic Task Scheduling with Load Balancing using Hybrid Particle Swarm Optimization.Int.J.Open Problems Compt.Math.,Vol.2,No.3,September 2009,ISSN 1998- 6262;Copyright@ICSRS Publication2009.

[35] Peng-Yeng Yin, Shiuh-Sheng Yu, Pei-Pei Wang, and Yi-Te Wang, "A hybrid particle swarm optimization algorithm for optimal task assignment in distributed systems", Computer Standards \& Interfaces , Vol.28(2006), pp.441-450.

[36] C.Kalpana,U.Karthick Kumar and R.Gogulan, Max- Min Particle Swarm Optimization Algorithm with Load Balancing for Distributed Task Scheduling on the Grid Environment. JCSI International Journal of Computer Science Issues, Vol. 9, Issue 3, No 1, May 2012 ISSN (Online): 1694-0814.

[37] C.Kalpana,U.Karthick Kumar and R.Gogulan,A Randomized load balancing algorithm in grid using Max Min PSO Algorithm. International Journal of Research in Computer ScienceeISSN 2249-8265

[38] Volume 2 Issue 3 (2012) pp. 17-23@ White Globe Publications.

[39] C.Kalpana,U.Karthick Kumar and R.Gogulan,A Randomized load balancing algorithm in grid using Max Min PSO Algorithm. International Journal of Research in Computer ScienceeISSN 2249-8265

[40] Volume 2 Issue 3 (2012) pp. 17-23@ White Globe Publications.

[41] Adil Baykaso lu, Lale Özbakır and Pınar Tapkan Artificial Bee Colony Algorithm and Its Application to Generalized Assignment Problem Source: Swarm Intelligence: Focus on Ant and Particle Swarm Optimization, Book edited by: Felix T. S. Chan and Manoj Kumar Tiwari, ISBN 978-3-902613-09-7, pp. 532, December 2007, Itech Education and Publishing, Vienna, Austria. 